\title{
SUCCESSFUL LEARNERS OF IRISH AS AN L2: MOTIVATION, IDENTITY AND LINGUISTIC MUDES
}

\author{
KEVIN PETIT \\ Université Lumière Lyon 2
}

\begin{abstract}
This article presents the results of a small-scale research conducted for a master's thesis on the motivation to learn Irish on the part of university students and members of the Gaelic society $A n$ Cumann Gaelach. In the light of questionnaires' results and interviews, the emphasis is placed on the links between motivation, identity, and potential key moments in learners' lives. Using an AMTB-type questionnaire $(n=45)$, the author puts to the test Dörnyei's Motivational Self System theory (2005) in the context of the learning of Irish by looking at the correlation between the motivational intensity of 45 students and six variables (Ideal L2 Self, Ought to Self, Ideal L2 Community, Instrumentality, Parental encouragement, and Role of teachers). The notion of Ideal L2 Self, or the capacity to picture oneself speaking an L2 in the future, clearly appears to be strongly correlated with the respondents' motivational intensity $(\mathrm{r}=.75 \mathrm{p}<.01)$, in accordance with Dörnyei's model. However results concerning extrinsic factors differ from previous research, putting forward distinctive features of the learning of minority languages. The second phase of the research looks at the language learning narratives of three An Cumann Gaelach's members through the qualitative analysis of three interview transcripts. The results clearly show that time spent in Irish summer colleges are linguistic mudes (Pujolar and Puigdevall 2015), or keymoments, which triggered the interest in the language for the three students interviewed.
\end{abstract}

Keywords: Irish, motivation, identity, linguistic mudes, minority languages

\section{Introduction}

The data presented in this paper was collected in 2012 for my master's thesis while I was in Ireland for an Erasmus exchange program in Trinity College. A few days after my arrival in Dublin in 2012, I read an article in the Irish Times by Patrick Freyne, which looked 'at some of the concepts that have shaped Irish 
identity over the past century'. Celticism, not being British, Catholicism, and craic [fun] were some of the themes mentioned, among others. But the 3000word-article made no mention of the Irish language which is the first official language of the Republic of Ireland and which has been spoken there since the arrival of the Celts on the island around $500 \mathrm{BC}$.

Irish is a compulsory subject in school and is thus taught for 12 years to every pupil. According to the last census in 2011, around 2\% of the population (77,185 people) declared they spoke Irish daily outside of the school system. In comparison, in the 1891 census, 664,387 answered that they spoke it every day outside of school. In that sense, Irish can be considered a minority language, and the state has implemented various schemes to revitalise it since the creation of the Republic in 1921. The latest scheme is The 20 year strategy for the Irish Language aiming at 250,000 daily speakers of Irish for 2030. One quarter of the daily speakers of Irish live in the rural regions called the Gaeltacht (representing 2.2\% of the population of the Republic), traditionally considered as Irish-speaking because of their higher percentage of native speakers. It is in those Gaelachtai that most Irish summer colleges can be found, where in 2011 more than 20,000 teenagers spent a few weeks learning the language with native speakers in an Irish-speaking environment (Ó Murchú 2014: 431).

The figures above show how important it is for the maintenance of the language to teach Irish as an L2 at school. This article focuses on language learning motivation and tries to identify the determining factors influencing it.

In university, Irish is not a compulsory subject, but some Irish language societies promote its use. For example, in Trinity College Dublin, An Cumann Gaelach was created in 1907 and its main goal is to provide opportunities for its 920 members to use Irish. They have a weekly chat group and yoga class, they publish a journal, and they organise other punctual events like debates, concerts, and weekend trips, all through Irish. They also obtained a room on campus in September 2012 where members can sit and have coffee while reading Irish magazines and chatting in Irish. They are also politically active, for example in December 2012 they submitted their suggestions and concerns to Trinity College authorities which were drafting a new Irish Language Policy Scheme for its campus. During the events I went to, apart from foreign students, the members proved to have the ability to discuss topics fluently in Irish, which they used in all their exchanges. As an exchange student, I was really interested in the situation of the Irish language, the motivation of learners, and the potential links between language learning and identity. An Cumann Gaelach was a convenient sample for my research as they were located on campus and offered a room to meet, they could be contacted very easily, and obviously they had an interest in Irish which made them eager to participate. I decided to submit an online questionnaire to their members and then to interview volunteers on the topic of their motivation to learn Irish. 
I will start in part one to explain in detail Dörnyei's (2005) theory on motivation and identity which provided me with tools for my research. The limits of this psycholinguistic model on motivation are also presented along with alternative ways of looking at the reasons why people learn a second language. The study of language learners' narratives along with the notion of mudes - defined as 'a critical juncture in the life cycle where a speaker changes linguistic practice in favour of the target language' (O'Rourke and Walsh 2014: 68) - are considered.

Part 2 presents the research I did for my master's thesis. First, the results of the questionnaires and their correlation analyses are presented and analysed. Then, the extracts from interviews retraces the learners' language learning narratives and look at how it can help understand An Cumann Gaelach members' motivation to learn Irish.

\section{Language learning and identity}

This part looks at some of the ways the notions of identity and language learning have been defined and linked together in the field of second language acquisition (SLA) research and sociolinguistics, along with their respective methodologies.

\subsection{From Integrative motivation to the L2 Motivational Self System}

In the 1970s social psychologists Robert Gardner and Wallace Lambert were interested in the often confrontational coexistence of the Anglophone and Francophone communities in Canada in the 1970s and the role of the learning of the other community's language in improving relationships. They believed that students' attitudes towards the other ethnolinguistic group greatly influenced the acquisition of the language of the latter. It is in this setting that Gardner concluded in 1985 that three main factors influenced language learning: Integrativeness, or the desire to communicate with members of an L2 community and sometimes even the desire to become like them; attitudes towards the learning situation, which include attitudes towards the language teacher and the class; and motivation, that is effort, desire and attitude towards learning the language. He referred to this configuration as 'integrative motive', which is defined as 'motivation to learn a second language because of positive feelings towards the community that speaks the language' (Gardner 1985: 82-83).

Gardner's Integrative Motivation Model was the dominant one in the L2 motivation field for three decades, but new advances in the 1990s and the concepts of self and identity lead to reframe L2 motivation as part of the self- 
system. This new orientation came from criticism of the concepts of integrativeness. Even though it was relevant in Gardner's environment where two ethnolinguistic communities were in contact, integrativeness cannot be applied in most L2 learning environments. Indeed most language learners are not in direct contact with the L2 community thus there is no realistic opportunity for integration. Also, in certain cases, situation-specific motives - such as the quality of the learning experience - overrode general negative language attitudinal dispositions as in studies on Israeli students learning Arabic (Donitsa-Schmidt, Inbar, and Shohamy 2004). Finally, studies of learners of English, which is both the official language of several countries and the most important lingua franca worldwide, pushed researchers to reinterpret integrativeness as the integration with a global community rather than the assimilation with the native speakers. To conclude, critics of Integrative motivation pointed out its monolingual bias and its essentialist belief that one community equals one language. Pavlenko and Blackledge (2004), in their book Negotiation of Identity in a Multilingual Context, called for a post-structuralist view of identity: they argued that identities are not fixed but they are negotiable and that some communities do not exist physically as coherent and easily definable groups, but exist in the learner's imagination. Thus they put forward the crucial role of 'imagined communities' and of imagination in the creation of new identity options. In other words, an integrative motivation from this perspective would be the desire to integrate an imagined L2 community which does not physically exists as a coherent and easily definable community but exists in the learner's imagination. This shift from the learner's social context to the learner's imagination is the starting point of (Dörnyei 2005) Motivational Self System.

Dörnyei wanted to re-conceptualise language learning motivation by focusing on the learner, and consequently he turned to psychology. He based his model on Markus and Nurius's concept of possible selves. Possible selves represent 'individuals' ideas of what they might become, what they would like to become, and what they are afraid of becoming' and consequently function as 'incentives for future behavior' (Markus and Nurius 1986: 954). Indeed Higgins, in his Self-discrepancy theory, differentiates the actual self - one's image of oneself - from self-guides. He describes self-guides as comprising the ideal self (one's personal wishes) and the ought-to self (one's sense of duty). The ideal selves have a promotion focus based on wishes and hopes of success and accomplishment, while the ought-to selves have a prevention focus based on obligations, the sense of duty, and responsibilities to avoid negative outcomes. The boundary between the ought-to self and the ideal self is not clear. It is better to imagine a continuum between the two, and the closer they are, the greater the motivation. What self-discrepancy tells us is that 'we are motivated to reach a condition where our self-concept matches our personally 
relevant self-guides' (Higgins 1987: 321). Or in other words we are inclined to reduce the discrepancy between who we are and who we want to become.

As a consequence he developed a new model, the Motivational Self System (Dörnyei and Ushioda 2009) consisting of three elements considered as the three major factors influencing motivated learning behaviour:

- Ideal L2 Self: if the person we would like to become speaks an L2, the Ideal L2 Self is a powerful motivator to learn the L2 because of the desire to reduce the discrepancy between our actual and ideal selves.

- Ought-to Self: attributes that one believes one ought to possess (ie, various duties, obligations, or responsibilities) in order to avoid possible negative outcomes.

- L2 Learning Experience: concerns situation-specific motives related to the immediate learning environment and experience (e.g. the impact of teacher, the curriculum, the experience of success).

The current dominant model to study language learners' motivation in the field of SLA is Dörnyei's L2 Motivational Self System. It stemmed from criticisms of Robert Gardner's Integrative motivation which focused on the role of the social context on motivation. On the other hand the L2 Motivational Self System, influenced by psychology and post-structuralist views of identity, considers learners and their selves as the central elements influencing motivated learning behaviour. Nonetheless, both models are quantitative in nature, depending on questionnaires and statistical analysis, a methodology that has come under criticism. As we will see in the next part, looking qualitatively at language learners' history can prove very useful to go a step further and understand the necessary conditions for motivation to be triggered during key moments, or linguistic mudes.

\subsection{Narratives and linguistic mudes}

The fact that Dörnyei's model depends on the correlation analysis of statistical results yielded by AMTB-type questionnaires (Attitude and Motivation Test Battery) developed by Gardner, while at the same time taking its distance from social psychology, has been the basis of Emma Ushioda's criticisms. She pointed out that 'possible selves imply individual subjective experience and perception, and the extent to which this individuality can be meaningfully captured through a quantitative measurement instrument that pre-defines respondent options seems questionable' (Ushioda 2012: 68). She goes on to argue that this methodology only produces linear cause-effect models when we should explore the reciprocal interaction between the self and a particular 
cultural, social, and historical context. In fact, she regrets that 'the unique local particularities of the person as self-reflective intentional agent, inherently part of and shaping her own context, seem to have no place in this kind of research' (Dörnyei and Ushioda 2009: 218). She deems it necessary to turn to socially and contextually grounded theoretical frameworks such as, among others, Norton's (2000) and Pavlenko and Blackledge's (2004), and to work on the discourse analysis of interviews, narratives, and diaries of language learners.

Turning to interviews and narratives to analyse them quantitatively and qualitatively can yield very interesting results as in Munoz's (2012) investigation on the existence and nature of turning points in L2 learners' trajectories. She interviewed 142 undergraduate students in an English Studies degree at a university in Spain about their present, past, and future language learning history. She observed that $85 \%$ of the students interviewed acknowledged experiencing a turning point in their language learning. That turning point occurred for roughly half of them during a stay abroad experience and for roughly a third of them during an intensive learning experience in a formal setting at home. The main themes identified in the interviewee's accounts concerning the nature of the turning points were agency - 'people's ability to make choices, take control, selfregulate' (Muñoz 2012: 148) - language practice - the constant use of the target language - and linguistic assimilation - the participant's realisation 'that during a stay abroad the second language is permeating her thoughts' (Muñoz 2012: 153) (It is worth noting how close the concepts of agency and self-discrepancy are). It is not absurd then to believe that key moments shape the way learners perceive their language learning.

As a matter of fact, Catalan sociolinguistics have brought into the foreground the notion of linguistic mudes. Mudes is a Catalan word 'referring to (often reversible) variations in social performance, such as dressing-up for an event or change appearance generally' (Pujolar and Puigdevall 2015: 168). When applied to language, mudes can be defined as 'a critical juncture in the life cycle where a speaker changes linguistic practice in favour of the target language' (O'Rourke and Walsh 2014: 68). By re-organising one's linguistic repertoire learners 'start projecting a new, different or additional linguistic persona' (Pujolar and Puigdevall 2015: 172). Mudes are the result of key moments where new social spaces and activities with new people eventually mean the new language gets socialised, which are not without reminding Dörnyei's conception of motivation. The difference being that sociolinguists talk about social persona with specific discursive position which can be recognised or contested in interaction, putting forward relations of power (Bourdieu 2001) which are not considered by Dörnyei.

In fact, Norton claims that 'SLA theory needs to develop a conception of identity that is understood with reference to larger, and frequently inequitable 
social structures which are reproduced in day-to-day social interactions' (Norton 2000: 5). Based on her qualitative study of migrant language learners in Canada, her book focuses on the unequal relation of power between language learners and target language speakers which constrains their access to the conditions for achieving communicative competence. In other words, certain social spaces enable identity options, while others constrain them. Identities are thus negotiated in linguistic and social interactions where each act of speaking (or silence) may constitute an act of identity (Pavlenko and Blackledge 2004).

In the introduction I described Dörnyei's L2 Motivational Self System to understand how identity and motivation in language learning are linked. According to Higgin's (1987) Self-discrepancy theory we are inclined to reduce the difference between who we are and who we want to become. This has led Dörnyei (Dörnyei and Ushioda 2009) to consider motivation as being made up of the Ideal L2 Self (the person one would like to become speaks an L2), the ought-to self (attributes that one believes one ought to possess) and the L2 learning experience. I then looked at how sociolinguistics can help us go a step further into our analysis by taking into consideration power relations inherent to any interaction (Bourdieu 2001). Indeed, if Dörnyei's model has enabled to empirically prove a relationship between identity and language learning, the social conditions for the inception and realisation of identity options are not looked upon. We have seen how key moments, the previously mentioned mudes (Pujolar and Puigdevall 2015), enable an L2 to get socialised and thus new linguistic persona to be imagined and performed. The rest of this article will try to use both a psycholinguistic and sociolinguistic approach to understand the motivation to learn Irish of members of the Gaelic society in Trinity College Dublin.

\section{A Case Study of Successful Learners of Irish}

The data analysed in this part consisted in the results of online questionnaires submitted to An Cumann Gaelach's members followed by the transcripts of interviews. The aim was to identify factors influencing language learning using Dörnyei's methodology, combined with a more qualitative analysis of interviews.

\subsection{The Ideal Irish Self: questionnaire's results and analysis}

\subsubsection{Participants}

The questionnaire was filled by forty five members of An Cumann Gaelach who were learners of Irish. They were aged between 17 and 60 with a mean age of 21.8, divided between 31 females and 14 males. From the twelve participants 
who claimed that their parents spoke Irish, two said their parents spoke it at home. Thirty-three respondents attended English schools from which four followed a special Irish curriculum. Nine respondents attended an Irish medium school, and the remaining three respondents were foreigners studying in TCD but who had been in secondary education in their home country (one Indian, one German, and one American).

\subsubsection{Instruments}

The scales and items were taken from previous established questionnaires on motivation (and then adapted to the Irish context) from Dörnyei and Clèment (2001), Taguchi, Magid and Papi (2009), Yashima (2009) and the 1999 Irish primary school pupil's attitude and motivation survey by Harris and Murtagh (1999). Five point Likert-scales were used and the respondents had to choose for each question one of the following answers: Strongly Disagree, Slightly Disagree, Neutral, Slightly Agree and Strongly Agree. When possible the scales were composed of an equal number of negatively and positively worded items. The questionnaire was composed of 54 items from ten scales followed by eight factual/personal questions. The criterion measure assessed students' motivational intensity. The nine variable scales were as follow:

Ideal L2 Irish Self: measures the importance of one's vivid Irish speaking facet of one's ideal self, or in other words one's ability to project one's self as a proficient Irish speaker in the future.

Ought to L2 Irish Self: measures the attributes that one believes one ought to possess concerning Irish (duties, obligations, responsibilities) in order to avoid negative outcomes.

Instrumentality: measures the potential beneficial influence on the labour market of a competence in Irish.

Parental Encouragement: measures the amount of help and support in learning Irish given by the respondents' parents.

Role of teachers: measures the amount of help and support by the respondents' teacher during their learning of Irish.

Ideal Irish Community: All the scales were taken from previous questionnaires mentioned above except this one. The particularity of this survey is that Irish is a minority language. Vitality, or perceived vitality, is an important factor in sustaining endangered languages. In addition a preliminary focus group had put forward the relative importance of this variable and its influence on motivation in the context of Irish. So this new scale measures the learner's confidence in the vitality and growth of the Irish speaking community in the future.

The three following scales did not reach internal consistency and thus will not be used in the analysis: 
Attitude to learning Irish: This scale was meant to measure the attitude produced by the actual experience of learning Irish. The items were phrased in order to consider any activity seen by the respondents as beneficial for his language as learning Irish, even outside of the formal setting of Irish language class. Consequently the items may have been too general and vague, not concentrating on particular experiences.

Attitude towards the Irish Community: This scale was supposed to measure learners' attitude towards Irish speakers. At the time I did not realise how ambiguous my questions were: what does being an 'Irish speaker' mean? Does it mean being a native speaker, a fluent L2 speaker (and when is one considered as being fluent?), or even someone who is learning the language? For example, I met fluent speakers of Irish who claimed some people would not consider them as authentic Irish speakers on the basis that they had learned it in Dublin (and not in the Gaeltacht) and had a Dublin accent. Debating these questions would usually bring about the issues of language legitimacy, authenticity and relations of power which we do not have time to touch upon in this article but which can be studied in Bourdieu (2001), Costa (2014), O'Rourke, Pujolar and Ramallo (2014), and particularly O'Rourke and Walsh (2014) as it focuses on the situation in Ireland.

Interest in Gaelic Culture: This scale was meant to measure learners' interest in Gaelic literature, cinema, and music.

\subsubsection{Procedure}

Six members of An Cumann Gaelach participated in a questionnaire piloting phase which brought into light some ambiguous items that were then rephrased. An invitation to fill in the questionnaire online was included in the weekly An Cumann Gaelach TCD newsletter sent by e-mail to all its members. From the 920 members of the society, only 45 answered the questionnaire. This low figure reflects the difference between the number of students who enrol in societies in September and the number of students who stay active members in societies all year long.

First the results of each scale and their items were studied. Then correlation analysis between scales was carried on using the statistical software SPSS version 20 . The five possible answers were coded from 1 to 5 as follow: Strongly agree $=5$, Slightly Agree $=4$, Neutral =3, Slightly disagree $=2$, and Strongly disagree $=1$. Negatively worded items were coded the opposite way (from Strongly agree $=1$, to Strongly Disagree =5). The internal consistency of each scale was measured using Cronbach Alpha $\alpha$. When necessary the scales were modified, i.e. items which were not consistent with the scale were deleted, to reach acceptable internal consistency. Three scales did not reach internal consistency even after modification, consequently they will not be used in the analysis (Attitude to Learning Irish $(\alpha=.43)$, Attitudes towards the Irish community $(\alpha=.58)$, and Interest in Gaelic Culture $(\alpha=.54))$. 


\subsubsection{Overview of the questionnaires' results}

For clarity the percentages of the responses for Strongly Agree and Slightly Agree were added up, and so were the responses for Strongly disagree and Slightly Disagree.

Motivation to learn Irish (criterion measure): There is no doubt that this group was highly motivated in learning Irish as $97 \%$ wanted to learn Irish as much as possible.

Ideal Irish Self: The respondents had a strong Ideal Irish self, 95\% of respondents could imagine themselves speaking in Irish with friends and colleagues in the future and $84 \%$ could imagine raising their child through Irish.

Ought to Irish Self: Only 56\% of the respondents experienced pressure to learn Irish from people around them, and even less (49\%) experienced pressure from their parents. A curious phenomena is that 58\% of the respondents answered that most people around them thought that learning Irish is a waste of time even if $89 \%$ claimed people around them wished they could speak better Irish, $71 \%$ claimed people around them thought that Irish was an advantage, and $54 \%$ claimed people around them thought it is fashionable. It seems like respondents experienced both negative and positive reactions about their learning of Irish and towards the language itself.

Ideal Irish Community: The scale showed mixed results because even if $87 \%$ of the respondents claimed that the Irish language would survive in the future and 58\% thought that it is spreading worldwide, only a minority believed people in Ireland would become bilingual (16\%) and would use it at home (27\%), and only $58 \%$ believed one day it would be possible to use any public service in Irish.

Instrumentality: Even though 52\% thought that Irish would not help them make a lot of money, $48 \%$ of the respondents answered they would need Irish for their career, 56\% thought employers considered Irish as an attractive feature when hiring personnel and 45\% thought Irish would help them get a good job.

Parental Encouragement: The results from the questions of this scale show that the support of parents is not as big as one would have imagined. Only 54\% of the respondents answered that their parents had helped them with their Irish, $43.5 \%$ said that their parents told them it was important to learn Irish, and $42 \%$ that their parents encouraged them to practise Irish as much as possible.

Role of teachers: The teachers seem to have had a bigger role than parents as $68 \%$ acknowledged that their teachers had had a positive influence on their learning. Still, 26\% claimed their Irish teachers had not played any role in their interest in Irish and 15\% even claimed that their Irish teachers had discouraged them from learning Irish. 


\subsubsection{Results of the correlation analysis}

The following table shows the result of the correlation between the criterion measure (i.e. motivation to learn Irish) and the six variables measured in the questionnaire:

Ideal Irish Self

Ought-to Self

Parental Encouragement

Ideal Irish Community

Role of Teachers

Instrumentality

\section{Criterion Measure}

$.75^{* *}$

$.34 *$

$.295^{*}$

$.64 * *$

.06

$.61 * *$

Note: $* \mathrm{p}<.05, * * \mathrm{p}<.01$

Table 1 : Correlation between Criterion Measure (i.e. Motivation to Learn Irish) and Other variables

What we can observe is that Parental Encouragement $(r=.295, \mathrm{p}<.05)$ and Role of teachers $(r=.06)$ have no significant relationship with Motivation to learn Irish. It should be noted that these results can only be generalised for Parental encouragement, as the correlation between Role of Teachers and the criterion measure has no statistical significance with a coefficient $\mathrm{p}>.05$.

Ought to L2 Self $(r=.34, \mathrm{p}<.05)$ is very close to be considered as having no relationship with Motivation to Learn Irish, but still seems to be slightly positively related with the later.

The three other variables have a significant positive correlation with Motivation to Learn Irish and have been ranked according to the strength of their relationship with the criterion measure: Ideal Irish Self $(r=.75 \mathrm{p}<.01)$, Ideal Irish Community $(r=.64 \mathrm{p}<.01)$, and Instrumentality $(r=.61 \mathrm{p}<.01)$.

\subsubsection{Discussion}

The results from the questionnaires showed that the respondents were highly motivated to learn Irish and that they could definitely picture themselves in the future speaking Irish with family, friends, and colleagues. They experienced both negative and positive reactions from people around them concerning their learning of Irish and towards the language itself, but the pressure felt from their social environment to learn Irish is limited. Regarding the correlation analysis, the fact the Ideal Irish Self is the most highly correlated variable with the motivation to learn Irish is in accordance with Dörnyei's Motivational Self System. The more 
students picture themselves as proficient speakers of Irish in the future, the more they are motivated to learn the language. On the other hand, the very slim correlation between the Ought-to self and the motivation to learn Irish seems to be in contradiction with Dörniey's model. But if we look at the general trend in the results, extrinsic motivational factors (Parental encouragement, Role of teachers, and the Ought-to self) were not (or nearly not) correlated with motivational intensity, while intrinsic factors (Ideal Irish Self, Ideal Irish Community) were. We can also put it this way: social pressure to learn Irish, when there was one, did not seem to influence learners' motivation. On the other hand, students' personal development and expectations for the future, which included using Irish, did influence their motivation. This lack of social pressure may be symptomatic of minority languages which do not benefit from prestige and have little or no symbolic value on the linguistic market. Instrumentality though, which is an extrinsic factor, was highly correlated with motivation. This brought to light a particularity of the group under scrutiny: it appeared that Irish could help professionally and had a certain value in the eyes of employers. We have to bear in mind that 14 of the respondents were majoring in Irish and most probably would become Irish teachers, while others might have been aiming at civil servant positions in Ireland or the European Union where Irish is still valued. This was statistically verified as students having Irish as a major appeared to possess a higher sense of instrumentality regarding the learning of Irish $(\mathrm{M}=14.4, \mathrm{SD}=4.1)$ than the others $(\mathrm{M}=11.5, \mathrm{SD}=3.4)$ which proved to be statistically significant $(\mathrm{t}(43)=2.6, \mathrm{p}<.05)$, and they were also more motivated $(\mathrm{M}=21.6, \mathrm{SD}=3.9)$ than the others $(M=19.1, S D=3.8)$ in a significant way $(t(43)=2.1, p<.05)$. Finally, the respondents expressed their beliefs that they will use Irish every day in different spheres (family, friends, colleagues) and their optimism about a growing Irish speaking community which some believe is spreading worldwide. Those beliefs are powerful motivators for them as shown by correlation analysis. But if students' parents and teachers did not influence students' motivation and if the ought-to self seems marginal, how did they come to love and use the language to the point where they have an image of themselves speaking it with friends, colleagues, and family in the future? The next part will try to answer this question by analysing qualitatively follow-up interviews.

\subsection{Learners' narratives}

\subsubsection{Procedure}

Even though we identified the Ideal Irish Self as a major factor of motivation for members of An Cumann Gaelach, an in depth understanding of the participants' motivation required more qualitative data which I decided to gather through 
individual semi-structured retrospective interviews. The aim was to confirm what we inferred from the quantitative data and to identify latent factors particular to this group which could not be measured by the questionnaires. The last item of the questionnaire was an open ended question in which I asked the respondents to leave any comment they wanted to and also to leave their e-mail address if they wanted to take part in research interviews. Ten respondents left their e-mail addresses and three (two females and one male) responded positively to my email asking if they were still available to help me in my research. All three interviews, which lasted between 30 and 40 minutes, were audio-recorded, transcribed for analysis and anonymised by changing the interviewees' names. I started the interview by asking the participants to tell me the story of their learning of Irish as far as they could remember it. Their narratives were studied and compared to look for key moments in their language learning history.

\subsubsection{Narratives}

Catherine went to an English medium school. She is a first year student of European studies with German and Russian and would like to work in EU institutions using her languages. She is not taking Irish classes anymore and she does not speak Irish with her parents because even though 'they did it in school [...] they don't have a high standard at all'. Catherine started her learning of Irish in English medium primary schools which she describes as learning words, using a textbook, doing homework and learning the grammar. She did not understand its relevance and she didn't grasp what she was really doing because 'no one is teaching it to you properly and you're not using it'. She remembers secondary teachers being frustrated by the poor level of Irish of pupils and states that 'there's definitely a problem in primary school'.

Mary went to a naionra, or Irish medium playschool, and then to Irish medium primary school but from age six she went to English medium schools. She is a second year student in psychology and studied some Irish in university last year (one Irish language class and two Irish literature classes). She sometimes talks in Irish to her mother who is a primary school teacher and has a high standard of Irish. She also mentions that she speaks with her boyfriend and a lot of her friends in Irish. Mary's mother started to teach her Irish because she wanted her daughter to go to Irish medium schools. Consequently Mary had always been good in Irish. She does not recall a lot from naionra or primary school except that she did not resent Irish however she did not consider it different from learning any other subject either.

Aidan is a law student from Dublin and he does not study Irish in university. His parents speak good Irish as his father's mother was an Irish teacher and her mother is a language teacher. Still he does not have full conversations with his parents but 
they do 'drop in an Irish phrase here and there, a bit of Irish vocabulary here and there'. Aidan and his three siblings were sent to Irish medium primary schools where he developed a good level of Irish and also an interest in the language. His enthusiasm for Irish grew even stronger when later he got to English medium secondary school, 'by virtue of not being in Irish education'.

Even though each interviewee had different Irish learning experiences they all ended up talking about Irish summer courses which were for all of them a determining experience. Catherine explains that from the age of 15 she went three times to Gaeltacht summer courses where she would speak Irish with her friends, learn the grammar, play sports and games through Irish. Compared to formal classes she says it was 'much more fun', 'easy', and 'real'. This experience made 'a big difference' to her and triggered 'that understanding of what it really was because you live with people who speak Irish all the time'. So much so that she claims that 'since then it's just been one of my favourite things in my life'. On top of that, learning languages for her is synonymous with meeting people: she explains that 'At the beginning I hated Irish as a subject but then [it changed] because I learned it as a method of communication and not as a subject'. Mary started going to summer camp every year since she was 10 , and when she was 16 she started to work there to supervise the kids and then to teach Irish. She describes it as a summer camp where they talked Irish all the time, they played games, had dances and fun through Irish, learned songs, learned how to say the mass and had one grammar class as well as one conversational class. She remembers that the emphasis was on speaking, that there were no writing classes. She met her boyfriend there and also a lot of friends with whom she speaks Irish so it is the reason why she 'started loving Irish'. Thus it was 'an eye opening experience' which made her realise that Irish was 'not just a school subject': she could make friends, play games and do sports through Irish. She explains that it was applied and practical compared to school which was all about learning a curriculum in order to get the leaving certificate. Aidan went to Irish course for five consecutive summers which maintained his interest in the language. More importantly, while he 'didn't improve that much in school', it is in the summer course that he really improved his Irish. He describes it as three weeks where you only heard and spoke Irish which made him become more fluent, acquire vocabulary, and achieve 'a stronger ear for Irish'. His experience of learning the language in secondary school was boring, not interesting, not enjoyable, and not motivating. He can understand that people who did not go to Irish summer course or all-Irish schools did not develop an interest in Irish.

Catherine explains that now the only way she works on her Irish is through An Cumann Gaelach and that she speaks Irish to friends and to her boyfriend. She also listens to Irish radio programmes sometimes. Mary too says that she 
does not use Irish as an academic subject any more but uses it to socialise every day in An Cumann Gaelach, on the phone or Facebook with her friends and her boyfriend. When I asked Aidan how he works on his Irish now, he answered 'It's not that I'm actively working on it it's just that it's part of my life'. He was granted Irish accommodation on campus which means his house mates are all enthusiastic Irish speakers. He is very involved in An Cumann Gaelach where he is in charge of the Irish magazine. So he speaks Irish daily and some weeks he ends up speaking more Irish than English.

The three interviewees said they felt they had 'a high standard of Irish', in the sense that none considered it necessary to take Irish language course any more, and they all claimed they used Irish on a daily basis with friends. For Aidan and Catherine, native speakers were models, an unattainable standard they still wanted to reach, to the point that Catherine acknowledged being jealous of native speakers.

All three concluded that teachers need to explain how Irish is more than a school subject, that it can be used outside of the classroom so that pupils understand the purpose of learning it. This quote from Aidan is a good summary of the point the three interviewees tried to make: 'if you could just get that into their [pupils'] mind-set that this can be part of your life when you leave school this can be important you can have a life with this language, I think that could have some kind of effect'

A few months after the interviews, I went back to the questionnaires and it was only then that I paid attention to two comments that respondents had left at the end of their questionnaires. They confirmed what came out of the three interviews:

The survey could pay more attention to the Irish colleges - the summer courses that thousands of students attend for weeks every summer. For many students, it is there and not in school that there interest in Irish is fostered.

There are no questions in this survey about Irish summer colleges which formed for me and for hundreds of people our age the true interest and love for Irish.

\subsubsection{Discussion}

From interviewing three students coming from very different educational backgrounds, what came out of their narratives confirmed and complemented the questionnaires' results. It was not in school or at home that the respondents really got interested in Irish, though it should be noted that they were raised in families which were very enthusiastic about the language. What made a big difference were the Irish summer colleges where they went as teenagers multiple times. It was described as an eye-opening experience which made them realise Irish was more than just a school subject. For the first time they were using the language every day for many different purposes like playing, doing sports and making 
friends. Since then, even though they do not take Irish class, they use Irish nearly daily with their friends. Their experiences in summer camps can be described as linguistic mudes (Pujolar and Puigdevall 2015). The Irish summer course was a new social space with new activities and new people which meant the Irish finally got socialised. The consequence for the three respondents seemed to be that the language became part of their lives as they now have social lives through Irish. In other words they developed a strong Ideal Irish Self in the summer college and became highly motivated to the point that they realised their ideal self.

\section{Conclusion}

This article focused on the factors influencing the learning motivation of Irish as an L2. The results of a study on members of the Gaelic society An Cumann Gaelach showed that the Ideal L2 Self is a powerful motivator for learners: the more the respondents could see themselves using Irish proficiently in the future with family, friends and colleagues, the more motivated they were. Respondents proved to be intrinsically motivated and comparatively extrinsic factors like the role of parents or teachers did not seem to have had a major impact on their motivation. Still, students with Irish as a major considered the learning of Irish as more instrumental and were more motivated than the other respondents. Employment opportunities where Irish is needed appear to have an influence on motivation. The results of the questionnaires, however, could not explain how the respondents developed such a strong Ideal L2 Self, so three interviews were carried out. The three respondents' language learning narratives clearly showed that a key moment, or linguistic mudes, for learners of Irish is the Irish summer college experience. For the first time the language becomes more than a subject because it is used to socialise. As a consequence Irish becomes part of everyday life for some of the learners, which may explain why the respondents managed to develop such a strong Ideal Irish self. The investment the interviewees put into learning Irish and the fact that it is now an inherent part of their social life emphasise the role Irish summer colleges can play on the development of motivation for learners of Irish. O'Rourke and Walsh (2014: 68) found, in a 50interview sample, that the 'Gaeltacht Muda' was the second most important stimulant for new speakers of Irish, right after muda at university due to the presence of a critical mass of fluent speakers there.

Further research is needed regarding the effective influence of the Irish college experience in Gaeltacht areas and in particular regarding its sustainability. Indeed, Mac Giolla Chríost has pointed out that: 
The results of the 2002 Census in the Republic of Ireland show that the notion of the Gaeltacht as a linguistically homogeneous and territorially coherent social entity cannot be sustained. [...] The total number of daily users of the Irish language within the Gaeltacht is almost half the number of daily users of the Irish language in the Greater Dublin Area. There are five times the number of daily users of Irish aged 3-4 years outside of the Gaeltacht than there are daily users of the language in the same age cohort within the Gaeltacht. (Mac Giolla Chríost 2005: 200-1)

The real ability summer colleges have to offer students an immersion experience should be assessed, and the absolute necessity of the Gaeltacht experience for developing students motivation can be questioned. The immersion aspect might not be as important as the symbolic/ideological implications and educational benefits of such experiences, as proved by the growing number of summer colleges in Dublin and other Galltacht areas (where English is the predominant language). It is telling that the Department of Arts, Heritage and the Gaeltacht, under the Gaeltacht Act (2012) is working on the development of Irish Language Networks, and that one of the latest chosen by Foras na Gaeilge in December 2015 is the Muintir Chrónáin Teo, situated 10 $\mathrm{km}$ west of Dublin. Thus the changing geographies of the Irish language lead to new challenges that need to be taken into consideration in further research to fully understand linguistic mudas and motivations of Irish learners.

\section{ACKNOWLEDGEMENTS}

The author is grateful to the ASLAN project (ANR-10-LABX-0081) of Université de Lyon, for its financial support within the program 'Investissements d'Avenir' (ANR-11-IDEX-0007) of the French government operated by the National Research Agency (ANR).

\section{REFERENCES}

Bourdieu, Pierre. 2001. Langage et pouvoir symbolique. Paris: Seuil.

Costa, James. 2015. 'New speakers, new language: on being a legitimate speaker of a minority language in Provence'. International Journal of the Sociology of Language 231: 127-145.

Donitsa-Schmidt, Smadar, Ofra Inbar and Elana Shohamy. 2004. 'The Effects of Teaching Spoken Arabic on Students' Attitudes and Motivation in Israel'. The Modern Language Journal 88(2): 217-228.

Dörnyei, Zoltán. 2005. The Psychology of the Language Learner: Individual differences in second language acquisition. Mahwah: Lawrence Erlbaum.

Dörnyei, Zoltán and Richard Clèment. 2001. 'Motivational characteristics of learning different target languages: Results of a nationwide survey', in Zoltán Dörnyei and R. Schmidt 
(eds.), Motivation and second language acquisition, Honolulu, HI: University of Hawaii Press, 399-432

Dörnyei, Zoltán and Ema Ushioda (eds.). 2009. Motivation, Language Identity and the L2 Self. Bristol, UK ; Buffalo, NY: Multilingual Matters.

Gardner, R. C. 1985. Social psychology and second language learning: the role of attitudes and motivation. London; Baltimore, Md., U.S.A: E. Arnold.

Harris, John and Lelia Murtagh. 1999. Teaching and Learning Irish in Primary School: a review of research and development. Dublin: Institiúid Teangeolaíochta Éireann.

Higgins, E. T. 1987. 'Self-discrepancy: A theory relating self and affect'. Psychological Review 94(3): 319-340.

Mac Giolla Chríost, Diarmait. 2005. The Irish Language in Ireland From Goidel to globalisation. New York: Routledge.

Markus, Hazel and Paula Nurius. 1986. 'Possible selves'. American Psychologist 41(9): 954-969.

Muñoz, Carmen (ed.). 2012. Intensive Exposure Experiences in Second Language Learning. Bristol, U.K.: Multilingual Matters.

Norton, Bonny. 2000. Identity and Language Learning: gender, ethnicity and educational change. Harlow: Pearson Education Limited.

Ó Murchú, Helen. 2014. More Facts About Irish (Vol. 2). Dublin: Comhdháil Náisiúnta na Gaeilge.

O'Rourke, Bernadette, Joan Pujolar and Fernando Ramallo. 2015. 'New speakers of minority languages: the challenging opportunity - Foreword'. International Journal of the Sociology of Language 231: 1-20.

O'Rourke, Bernadette and John Walsh. 2015. 'New speakers of Irish: shifting boundaries across time and space'. International Journal of the Sociology of Language 231: 63-83.

Pavlenko, Aneta and Adrian Blackledge (eds.). 2004. Negotiation of identities in multilingual contexts. Clevedon, UK: Multilingual Matters.

Pujolar, Joan, and Maite Puigdevall. 2015. 'Linguistic mudes: how to become a new speaker in Catalonia'. International Journal of the Sociology of Language 231: 167-187.

Taguchi, Tatsuya, Michael Magid and Mostafa Papi. 2009. 'The L2 Motivational Self System among Japanese, Chinese and Iranian Learners of English: A Comparative Study', in Zoltán Dörnyei and E. Ushioda (eds.). Motivation, language identity and the L2 self. Bristol: Multilingual Matters, 66-97.

Ushioda, Ema. 2012. 'Motivation: L2 Learning a Special Case?', in: S. Mercer, S. Ryan, and M. Williams. Psychology for Language Learning. Basingstoke: Palgrave Macmillan.

Yashima, Tomoko. 2009. 'International posture and the ideal L2 self in the Japanese EFL Context', in Zoltán Dörnyei and Ema Ushioda (eds.). Motivation, language identity and the L2 self. Bristol: Multilingual Matters, 144-163. 